\title{
Uterine Corpus Atypical Polypoid Adenomyoma
}

National Cancer Institute

\section{Source}

National Cancer Institute. Uterine Corpus Atypical Polypoid Adenomyoma. NCI

Thesaurus. Code C40235.

An adenomyoma that arises from the uterine corpus and is characterized by the

presence of marked glandular architectural complexity. It may recur following excision. 